South-Western Division.-The Autumn Meeting will be held, by the courtesy of Dr. Blachford, at the Bristol Asylum, Fishponds, on Friday, October 27th, IgI I. Northern and Midland Division.-The Autumn Meeting will be held, by the courtesy of Dr. Sankey, at Boreatton Park, Salop, on Thursday, October 19th, 1911 .

Scottish Division.-The Autumn Meeting will be held on Friday, November 17 th, 1911.

Irish Division.-The Autumn Meeting will be held on Thursday, November 2nd, 1911 .

\title{
APPOINTMENTS.
}

Cormac, H. Dove, M.B., M.S., Madras, Senior Assistant Medical Officer, Cheshire County Asylum, Parkside.

Gilfillan, S. J., M.B., C.M.Edin., Medical Superintendent, Colney Hatch Asylum.

Martin, Mary E., L.R.C.P. \& S.Edin., L.F.P.S.Glasg., L.S.A., Assistant Medical Officer, Bailbrook House, Bath.

Parkin, G. G., M.B., Ch.B.Vict., Second Assistant Medical Officer, Cheshire County Asylum, Parkside.

Petrie, Gavin E., M.B., Ch.B.Aberd., Third Assistant Medical Officer, Cheshire County Asylum, Parkside.

\section{PHOTOGRAPHIC GROUP OF THE DUBLIN MEETING.}

Photographic groups of members of the Association, taken at the garden party in the Zoological Gardens, may be had from Messrs. Werner and Son, 39, Grafton Street, Dublin. Price, in silver type, $6 s$. each. 